\title{
Self-harm in midlife: analysis using data from the Multicentre Study of Self-harm in England
}

Caroline Clements, Keith Hawton, Galit Geulayov, Keith Waters, Jennifer Ness, Muzamal Rehman, Ellen Townsend, Louis Appleby and Nav Kapur

\section{Background}

In England suicide rates are highest in midlife (defined as age 40-59). Despite a strong link with suicide there has been little focus on self-harm in this age group.

\section{Aim}

To describe characteristics and treatment needs of people in midlife who present to hospital following self-harm.

\section{Method}

Data from the Multicentre Study of Self-harm in England were used to examine rates over time and characteristics of men and women who self-harm in midlife. Data (2000-2013) were collected via specialist assessments or hospital records. Trends were assessed by negative binomial regression models.

Comparative analysis used logistic regression models for binary outcomes. Repetition and suicide mortality were assessed by cox proportional hazards models.

\section{Results}

A quarter of self-harm presentations were made by people in midlife ( $n=24599,26 \%)$. Incidence rates increased over time in men, especially after 2008 (incidence rate ratio [IRR] 1.07, $95 \% \mathrm{Cl}$ $1.02-1.12, P<0.01)$, and were positively correlated with national suicide incidence rates $(r=0.52, P=0.05)$. Rates in women remained relatively stable (IRR $1.00,95 \% \mathrm{Cl} 1.00-1.02, P=0.39$ ) and were not correlated with suicide. Alcohol use, unemployment, housing and financial factors were more common in men; whereas indicators of poor mental health were more common in women. In men and women 12-month repetition was $25 \%$, and during follow-up $2.8 \%$ of men and $1.2 \%$ of women died by suicide.

\section{Conclusion}

Self-harm in midlife represents a key target for intervention. Addressing underlying issues, alcohol use and economic factors may help prevent further self-harm and suicide.

\section{Declaration of interest}

K.H. and N.K. are members of the Department of Health's National Suicide Prevention Advisory Group. N.K. chaired the National Institute for Health and Care Excellence (NICE) guideline development group for the longer-term management of selfharm and the NICE Topic Expert Group which developed the quality standards for self-harm services. N.K. also chairs the NICE guideline committee for the management of depression. All other authors declare no conflict of interest.

\section{Keywords}

Self-harm; epidemiology; suicide.

\section{Copyright and usage}

(c) The Royal College of Psychiatrists 2019.
Self-harm is an important national and international public health issue. ${ }^{1,2}$ Defined as any act of self-poisoning or self-injury (selfinjury includes any injury to the body such as that from cutting or scratching, as well as more lethal methods involving, for example, hanging or jumping from a height) irrespective of apparent motivation, ${ }^{3}$ self-harm is a strong predictor of future suicide and therefore features prominently in suicide prevention strategies. ${ }^{1,2}$ In England the highest suicide rates are in men and women aged 40-59 years, with rates in men increasing to a peak of 25 suicides per 100000 population in 2013. Similar increases in suicide by men in midlife have been found internationally, including in North America ${ }^{4}$ and Australia. ${ }^{5}$ Given the strong link between self-harm and suicide, ${ }^{6,7}$ a concomitant increase in rates of self-harm in this age group would be expected. Recent trends in self-harm in England support this hypothesis, with rates of self-harm in men highest in the 35-54 years age group and an increase in rates in men aged over 55 years. ${ }^{8}$ Increased economic hardship has been suggested as a reason for the increase in suicide rates in midlife and may be detected in individuals who present to hospital for self-harm. ${ }^{9-12}$ Few studies have explored self-harm in men and women in midlife in detail. Broader studies that present information on self-harm by age give some indication of the characteristics common in this age-group, such as increased alcohol use ${ }^{13}$ and physical health problems. ${ }^{14}$ However, the lack of a defined midlife age group equivalent to that used in suicide statistics makes it difficult to accurately describe self-harm by people in midlife, and to identify the unique treatment needs of this group. The aim of this study was to describe self-harm in men and women aged 40-59 years, using data from the Multicentre Study of Self-harm in England. The specific objectives were to describe incidence rates and trends in self-harm over time in men and women in midlife, compare key characteristics of men and women, explore outcomes including repetition of self-harm and mortality by suicide, and to identify possible differences in subgroups (i.e. history or no history of previous self-harm and period effects of first presentation early or late in the study period) of those who self-harm in midlife.

\section{Method}

\section{Sample}

This study used observational data from the Multicentre Study of Self-harm in England, which holds information on hospital presentations for self-harm in Oxford, Manchester and Derby. Detailed data on mental state, psychiatric history, risks and needs were collected via completion of assessments by psychiatric staff in Oxford and Derby, and by psychiatric and/or emergency department staff in Manchester. These assessments were conducted as part of routine clinical care, which was broadly similar between hospital sites. Although the data were ultimately provided by the patient, some clinician interpretation of information provided during the assessment may be necessary, for example in reporting problems that precipitated self-harm. More limited data were collected on self-harm presentations that did not receive an assessment via searches of emergency department databases and patient records. Reason for non-assessment are unknown but may 
include self-discharge, not being offered an assessment or not waiting to be seen. Age, gender, date of self-harm and details of the method of self-harm were therefore available for the majority of episodes and individuals included in the analyses (further details of the scope and methods used in the Multicentre Study of Self-harm in England are available elsewhere, see Hawton et al $2007^{15}$ ). The Multicentre Study database includes complete information on self-harm presentations from 1 January 2000 to 31 December 2013 in Oxford and Derby, and from 1 January 2003 onwards in Manchester. Between 2000 and 2002, Manchester data were restricted to only those presentations where the individual received a specialist psychiatric assessment.

\section{The midlife age group}

Midlife was defined as people aged $40-59$ years. This age group was selected to match the age groups with the highest suicide rates in men and women reported by the Office for National Statistics (ONS; http://www.ons.gov.uk), ${ }^{16}$ as well as with a body of sociological work that identifies people in this age group as having a differential status in a number of work, health and social factors when compared with older and younger people. ${ }^{17-20}$

\section{Rates of self-harm}

Rates of self-harm were calculated based on the first self-harm presentation for each individual in the midlife age group within each calendar year. Denominator data were local authority population estimates, by year, from the ONS for Oxford City, City of Manchester and Derby Unitary Area where the Multicentre Study has near-complete capture of self-harm presentations. Rates were calculated per 100000 population. Self-harm figures for Manchester were adjusted up by a factor of 1.42 from 2000 to 2002 to compensate for the lack of data on non-assessed cases during this period. This calculation was based on a review of all self-harm attendances to emergency departments in Manchester between 1 September 2002 and 31 August 2003 and accounts for the overall proportion of non-assessed episodes.

\section{Suicide rates and mortality data}

To examine associations between self-harm rates and suicide rates for people in midlife in England, national rates of suicide from ONS were used. These statistics included all individuals where a death had an underlying cause of self-harm, or injury or poisoning of undetermined intent. ${ }^{16}$ Coroners only record a conclusion of suicide when it is 'beyond reasonable doubt'. It is usual practice in UK suicide research to include events of undetermined intent as these have been found to include a high proportion of suicides (accidental deaths were excluded, although some suicide deaths may also be included in this category). ${ }^{21-23}$ For mortality followup, the study file was linked to ONS mortality and National Health Service (NHS) contact data supplied by the Health and Social Care Information Centre (now NHS Digital, see http:// www.digital.nhs.uk). Individuals were traced up to 31 December 2015 to give a minimum 2-year follow-up period: follow-up ended if notification was received via the data linkage that an individual had died or emigrated outside of the UK. Cause of death was based on ICD-10 (1992) codes for suicide or event of undetermined intent (i.e. X60-X84 and Y10-Y34). Only 1.2\% ( $n=156)$ of midlife cases could not be followed up due to insufficient information available to identify a match; these were excluded from the mortality follow-up analysis. Time to death was based on index episode to maintain consistency with the comparative analyses.

\section{Repetition of self-harm}

Repetition of self-harm was calculated as a repeat presentation to hospitals in the same study area by the same individual within 12 months of their first self-harm episode in each calendar year. Data from 2003 to 2012 were included to allow 12 months follow-up.

\section{Midlife subgroup comparisons}

Individuals in midlife were allocated to two groups based on (a) a selfreported history of previous self-harm or (b) a self-reported lifetime first episode of self-harm at the first presentation recorded on the study database. Although responses are considered to be self-reported in general, it is also possible that clinicians may use personal knowledge of the patient or previous hospital records to report a history of selfharm. Further ascertainment of the veracity of self-reported history of self-harm is beyond the current scope of the Multicentre project. To examine any period or cohort effects of time of first presentation, those with a first presentation early in the study period (2002-2007) were compared with those who presented for the first time later in the study period (2008-2013). These cohorts were chosen to reflect equal time periods before and after the economic recession in 2008.

\section{Ethical approval}

The monitoring systems in Oxford and Derby have approval from local research ethics committees (Oxford: South Central Berkshire REC, 08/H0607/7; Derby: Derbyshire REC, 06/Q2401/84) to collect data on self-harm for local and multicentre projects. Selfharm monitoring in Manchester is part of a clinical audit system and has been ratified as such by the local research ethics committee (South Manchester REC). All three monitoring systems are fully compliant with the Data Protection Act of 1998. All centres have approval under Section 251 of the NHS Act 2006 (formerly Section 60, Health and Social Care Act 2001) to collect patient-identifiable information without patient consent.

\section{Statistical analyses}

Trends in rates of self-harm for men and women were assessed by negative binomial regression models to account for overdispersion in the data. Spearman's rho tests were used to measure the association between rate of self-harm and national suicide rate.

Characteristics $\times$ gender were compared by single-variable logistic regression. Analyses were at the individual level, based on the first recorded presentation for self-harm at age 40-59 years within the study period (i.e. the index episode). Core data on methods used in self-harm were available for all individuals in midlife, but more detailed information (e.g. history of psychiatric care, precipitating problems) were only available for individuals who received a specialist assessment and/or an assessment by emergency department staff in Manchester, therefore only assessed cases were included in the analyses (see Table 1 for full list of variables). A complete-case analysis approach was used to handle missing data whereby only cases with valid responses within a variable were included in analyses of that variable. Subgroup analyses used the same statistical approach but compared within rather than between genders.

To assess outcomes in terms of repetition of self-harm and mortality, basic frequencies and proportions were presented alongside Cox proportional hazards models to compare risk $\times$ gender. Multiple variable models were run including four additional variables likely to influence repetition of self-harm in people in midlife (unemployment, previous self-harm, alcohol use problems and being a current psychiatric in-patient) to assess the strength of the influence of gender on further self-harm and risk of suicide.

All analyses were carried out using Stata version 15.1 IC for Windows. 
Table 1 Comparison of characteristics of men and women who presented to hospital for self-harm aged 40 to 59 years, between 2000 and 2013

\begin{tabular}{|c|c|c|c|c|}
\hline Variable (all cases) & $\begin{array}{l}\text { Men, } n(\%) \\
(n=5886)\end{array}$ & $\begin{array}{l}\text { Women, } n(\%) \\
(n=6715)\end{array}$ & Odds ratio $(95 \% \mathrm{Cl})$ & $P$ \\
\hline \multicolumn{5}{|l|}{ Method of harm } \\
\hline Self-poisoning only & $4628(78.6)$ & $5829(86.8)$ & $0.56(0.51-0.61)$ & $<0.01$ \\
\hline Self-injury only & $1055(17.9)$ & $747(11.1)$ & $1.74(1.58-1.93)$ & $<0.01$ \\
\hline Self-poisoning and self-injury & $203(3.5)$ & $139(2.1)$ & $1.69(1.36-2.10)$ & $<0.01$ \\
\hline \multicolumn{5}{|l|}{ Method of injury ${ }^{a}$} \\
\hline Cutting or stabbing & 767 (61.3) & $648(73.4)$ & $0.57(0.48-0.69)$ & $<0.01$ \\
\hline Jumping from a height & $53(4.2)$ & $32(3.6)$ & $1.18(0.75-1.83)$ & 0.48 \\
\hline Hanging or asphyxiation & $148(11.8)$ & $54(6.1)$ & $2.06(1.49-2.85)$ & $<0.01$ \\
\hline Carbon monoxide gas & $73(5.8)$ & $9(1.0)$ & $6.01(2.99-12.08)$ & $<0.01$ \\
\hline Drowning & $22(1.76)$ & $18(2.0)$ & $0.86(0.46-1.61)$ & 0.64 \\
\hline Gunshot & $6(0.5)$ & 0 & - & - \\
\hline Traffic & $34(2.7)$ & $16(1.8)$ & $1.51(0.83-2.76)$ & 0.18 \\
\hline Other methods of injury & $139(11.1)$ & $97(11.0)$ & $1.01(0.77-1.33)$ & 0.93 \\
\hline \multicolumn{5}{|l|}{ Drugs taken in overdose ${ }^{a}$} \\
\hline Major tranquiliser/antipsychotic & $337(7.2)$ & $381(6.6)$ & $1.11(0.95-1.29)$ & 0.18 \\
\hline Benzodiazepines & $817(17.5)$ & $1095(18.8)$ & $0.92(0.83-1.01)$ & 0.08 \\
\hline Tricyclic antidepressants & $438(9.5)$ & $613(10.6)$ & $0.88(0.77-1.00)$ & 0.05 \\
\hline SSRI/SNRI antidepressants & $780(16.8)$ & $1167(20.2)$ & $0.80(0.72-0.88)$ & $<0.01$ \\
\hline Pure paracetamol & $1197(25.8)$ & $1460(25.3)$ & $1.03(0.94-1.12)$ & 0.52 \\
\hline Paracetamol combination drug & $494(10.7)$ & $678(11.7)$ & $0.90(0.79-1.01)$ & 0.08 \\
\hline Salicylate (pure and in combination) & $219(4.7)$ & $202(3.5)$ & $1.37(1.13-1.66)$ & $<0.01$ \\
\hline Co-proxamol & $63(1.4)$ & $113(2.0)$ & $0.69(0.51-0.94)$ & 0.02 \\
\hline Other named drug & $2178(46.7)$ & $2514(43.2)$ & $1.15(1.06-1.24)$ & $<0.01$ \\
\hline Non-ingestible substances & $77(1.6)$ & $48(0.8)$ & $2.00(1.39-2.87)$ & $<0.01$ \\
\hline Received a specialist assessment & $4158(61.2)$ & $4832(61.3)$ & $0.94(0.87-1.01)$ & 0.11 \\
\hline Variable (assessed cases only) & $\begin{array}{l}\text { Men, } n(\%) \\
(n=4158)\end{array}$ & $\begin{array}{l}\text { Women, } n(\%) \\
\quad(n=4832)\end{array}$ & Odds ratio $(95 \% \mathrm{Cl})$ & $P$ \\
\hline Alcohol consumed at time of self-harm & $2534(66.4)$ & $2741(61.9)$ & $1.22(1.11-1.33)$ & $<0.01$ \\
\hline \multicolumn{5}{|l|}{ Employment status } \\
\hline Employed & $1498(39.4)$ & $1694(38.8)$ & $1.03(0.94-1.12)$ & 0.58 \\
\hline Unemployed & $1492(39.2)$ & $1366(31.3)$ & $1.42(1.29-1.55)$ & $<0.01$ \\
\hline Registered for sickness/disability benefits & $668(17.6)$ & $712(16.3)$ & $1.09(0.97-1.23)$ & 0.13 \\
\hline Household duties & $11(0.3)$ & $457(10.5)$ & $0.02(0.01-0.05)$ & $<0.01$ \\
\hline Retired & $56(1.5)$ & $49(1.1)$ & $1.32(0.90-1.94)$ & 0.16 \\
\hline Student & $15(0.4)$ & $33(0.8)$ & $0.52(0.28-0.96)$ & 0.04 \\
\hline Other employment & $65(1.7)$ & $58(1.3)$ & $1.29(0.90-1.84)$ & 0.17 \\
\hline \multicolumn{5}{|l|}{ Ethnicity } \\
\hline White & 3591 (95.2) & $4126(94.3)$ & $1.19(0.98-1.45)$ & 0.08 \\
\hline South Asian & $71(1.9)$ & $99(2.3)$ & $0.83(0.61-1.13)$ & 0.23 \\
\hline Black & $49(1.3)$ & $76(1.7)$ & $0.74(0.52-1.07)$ & 0.11 \\
\hline Other & $61(1.6)$ & $73(1.7)$ & $0.97(0.69-1.36)$ & 0.86 \\
\hline Any previous self-harm (self-reported) & $2006(53.5)$ & $2525(57.6)$ & $0.85(0.78-0.93)$ & $<0.01$ \\
\hline Self-harm within 12 months & $820(21.9)$ & 862(19.7) & $1.14(1.03-1.27)$ & 0.01 \\
\hline Self-harm more than 12 months ago & $1120(29.9)$ & $1589(36.2)$ & $0.75(0.68-0.82)$ & $<0.01$ \\
\hline Current psychiatric treatment & $1777(45.8)$ & $2365(52.0)$ & $0.78(0.72-0.85)$ & $<0.01$ \\
\hline Out-patient care & $850(21.9)$ & $1040(22.9)$ & $0.95(0.86-1.05)$ & 0.29 \\
\hline In-patient care & $20(0.5)$ & $21(0.5)$ & $1.12(0.60-2.06)$ & 0.72 \\
\hline Previous psychiatric treatment (under secondary mental health services) & $2201(58.1)$ & $2706(60.7)$ & $0.90(0.82-0.98)$ & 0.01 \\
\hline \multicolumn{5}{|l|}{ Referral from the emergency department ${ }^{b}$} \\
\hline Admitted to medical bed & $2240(71.4)$ & $2733(73.7)$ & $0.89(0.80-0.99)$ & 0.04 \\
\hline Psychiatric out-patient care & $1426(34.3)$ & $1694(35.2)$ & $0.96(0.88-1.05)$ & 0.42 \\
\hline Psychiatric in-patient care & $376(9.0)$ & $280(5.8)$ & $1.62(1.38-1.91)$ & $<0.01$ \\
\hline Self-discharged & $86(2.1)$ & $93(1.9)$ & $1.08(0.80-1.45)$ & 0.63 \\
\hline General practitioner care ${ }^{c}$ & $1979(50.1)$ & $2478(54.5)$ & $0.84(0.77-0.91)$ & $<0.01$ \\
\hline Drug and alcohol services & $378(9.4)$ & $275(5.8)$ & $1.69(1.43-1.98)$ & $<0.01$ \\
\hline \multicolumn{5}{|l|}{ Precipitants of self-harm } \\
\hline Relationship problems: partner/family/friends/others & $2192(52.7)$ & $2946(61.0)$ & $0.71(0.66-0.78)$ & $<0.01$ \\
\hline Employment or study problems & $864(21.7)$ & $624(13.5)$ & $1.78(1.59-1.99)$ & $<0.01$ \\
\hline Financial problems & $833(20.9)$ & 795 (17.2) & $1.28(1.14-1.42)$ & $<0.01$ \\
\hline Housing problems & $681(17.1)$ & $570(12.3)$ & $1.47(1.30-1.66)$ & $<0.01$ \\
\hline Legal problems & $288(7.2)$ & $170(3.7)$ & $2.04(1.68-2.48)$ & $<0.01$ \\
\hline Alcohol problems ${ }^{d}$ & $1078(34.1)$ & $930(25.3)$ & $1.53(1.38-1.70)$ & $<0.01$ \\
\hline Drug problems ${ }^{d}$ & 199 (6.3) & $110(3.0)$ & $2.18(1.72-2.77)$ & $<0.01$ \\
\hline Physical health problems & $642(16.1)$ & $703(15.2)$ & $1.07(0.95-1.20)$ & 0.24 \\
\hline Mental health problems & $1008(25.3)$ & $1289(27.8)$ & $0.88(0.80-0.97)$ & 0.01 \\
\hline \multicolumn{5}{|l|}{$\begin{array}{l}\text { SSRI, selective serotonin reuptake inhibitor; SNRI, serotonin-noradrenaline reuptake inhibitor. } \\
\text { a. Denominator derived from valid responses within the self-injury or self-poisoning subgroup. } \\
\text { b. Data from Manchester only available from } 2004 \text { onwards. } \\
\text { c. Data only available for Manchester and Derby. } \\
\text { d. Manchester data only available from } 2006 \text { onward. }\end{array}$} \\
\hline
\end{tabular}




\section{Results}

During the study period (1 January 2000 to 31 December 2013) there were 24599 presentations to study hospitals by people in midlife (age 40-59 years), representing 26\% of all presentations on the Multicentre Study database; 11267 (46\%) were presentations by men and $13332(54 \%)$ were by women. These presentations were made by $5886(47 \%)$ men and $6715(53 \%)$ women. A total of $61 \%$ of men and women in midlife received a specialist psychiatric assessment in the emergency department.

\section{Rates of self-harm}

During 2000-2013 the overall rate of self-harm in midlife was 363 per 100000 population for men and 449 per 100000 population for women. Figure 1 shows rates over time $\times$ gender. Regression models showed a small increase in rates over time in men (incidence rate ratio [IRR] 1.01, 95\% CI 1.00-1.02, $P=0.03$ ), but not in women (IRR $1.00,95 \%$ CI $1.00-1.02, P=0.39$ ). Inspection of Fig. 1 suggested rates in men increased more rapidly after 2008. Further analyses confirmed a difference in trends in rate of self-harm in the period before 2008 (IRR 0.98, 95\% CI 0.95-1.00, $P=0.05$ ) and after (IRR 1.07, 95\% CI 1.02-1.12, $P<0.01$ ).

Figure 2 shows rates of self-harm in the Multicentre Study and national rates of suicide over time in men and women in midlife. Rates of self-harm were moderately correlated with age-matched suicide rates during the study period in men $(r=0.52, P=0.05)$, but not in women $(r=0.12, P=0.69)$.

\section{Self-harm in midlife}

Table 1 shows the characteristics of self-harm by men and women in midlife. Self-poisoning was the most used method but less common in men than in women (odds ratio $0.56,95 \%$ CI $0.51-0.61, P<0.01$ ), with self-injury more common in men (odds ratio $1.74,95 \%$ CI $1.58-1.93, P<0.01)$. Men were more likely to have consumed alcohol within $6 \mathrm{~h}$ of self-harm (odds ratio 1.22 , 95\% CI 1.11$1.33, P<0.01)$, but alcohol use was frequent in both genders $(66 \%$ of men and $62 \%$ of women).

Men were more likely to be unemployed (odds ratio $1.42,95 \%$ CI 1.29-1.55, $P<0.01)$. Previous self-harm was lower in men compared with women (odds ratio $0.85,95 \%$ CI $0.78-0.93, P<0.01$ ).
Current (odds ratio $0.78,95 \%$ CI $0.72-0.85, P<0.01$ ) and previous (odds ratio $0.90,95 \%$ CI $0.82-0.98, P=0.01$ ) psychiatric care was less likely among men. Men were more often referred to drug and alcohol services from the emergency department (odds ratio 1.69, $95 \%$ CI 1.43-1.98, $P<0.01$ ) compared with women, but proportions were low across both groups.

In terms of problems that precipitated self-harm, men reported problems with relationships (odds ratio $0.71,95 \%$ CI $0.66-0.78, P<$ 0.01 ) less often than women, but problems with employment (odds ratio $1.78,95 \%$ CI $1.59-1.99, P<0.01$ ), finances (odds ratio 1.28 , 95\% CI 1.14-1.42, $P<0.01$ ), housing (odds ratio $1.47,95 \%$ CI $1.30-1.66, P<0.01$ ) and alcohol (odds ratio $1.53,95 \%$ CI $1.38-$ $1.70, P<0.01)$ were more common in men than women in midlife.

\section{Comparison of 2002-2007 and 2008-2013 cohorts}

There were 3512 (46\%) men and 4063 (54\%) women included in the cohort comparison (see Table S1 available at https://doi.org/10. 1192/bjp.2019.90). Between 2002 and 2007, 1752 men and 2058 women had a first presentation for self-harm in midlife, whereas 1760 men and 2005 women had a first presentation for self-harm from 2008 to 2013. Detailed results of the cohort comparison are shown in Table 2.

Key results showed that men and women in the more recent cohort showed an increase in self-injury alone as a method of harm (men odds ratio 1.62, 5\% CI 1.40-1.87, $P<0.01$; women odds ratio $1.60,95 \%$ CI 1.36-1.89, $P<0.01$ ), higher unemployment (men odds ratio 1.67, 95\% CI 1.45-1.92, $P<0.01$; women odds ratio $1.58,1.37-1.82, P<0.01)$ and an increase in receipt of current psychiatric care (men odds ratio $1.57,95 \%$ CI $1.37-1.80, P<0.01$; women odds ratio $1.40,95 \% \mathrm{CI} 1.23-1.59, P<0.01)$. In regards to precipitating problems, issues around employment, finances and housing were particularly prominent in the later cohort (see Table 2 for details).

\section{History of self-harm versus lifetime first episode of self- harm in midlife}

There were 2006 (53\%) men and 2525 (58\%) women with a history of self-harm at the first recorded presentation for self-harm, and $1744(47 \%)$ men and 1860 (42\%) women who reported the presentation as a lifetime first episode of self-harm.

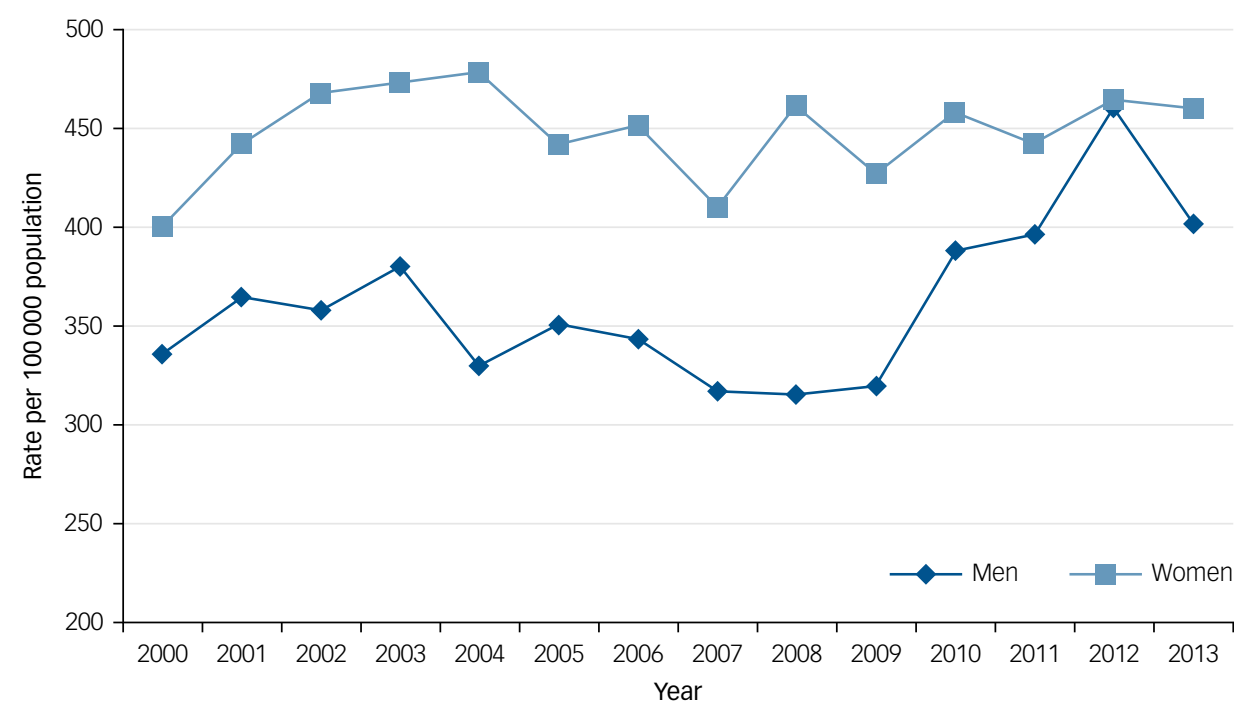

Fig. 1 Rate of self-harm in men and women aged 40 to 59 years, per 100000 of the age-matched population. 

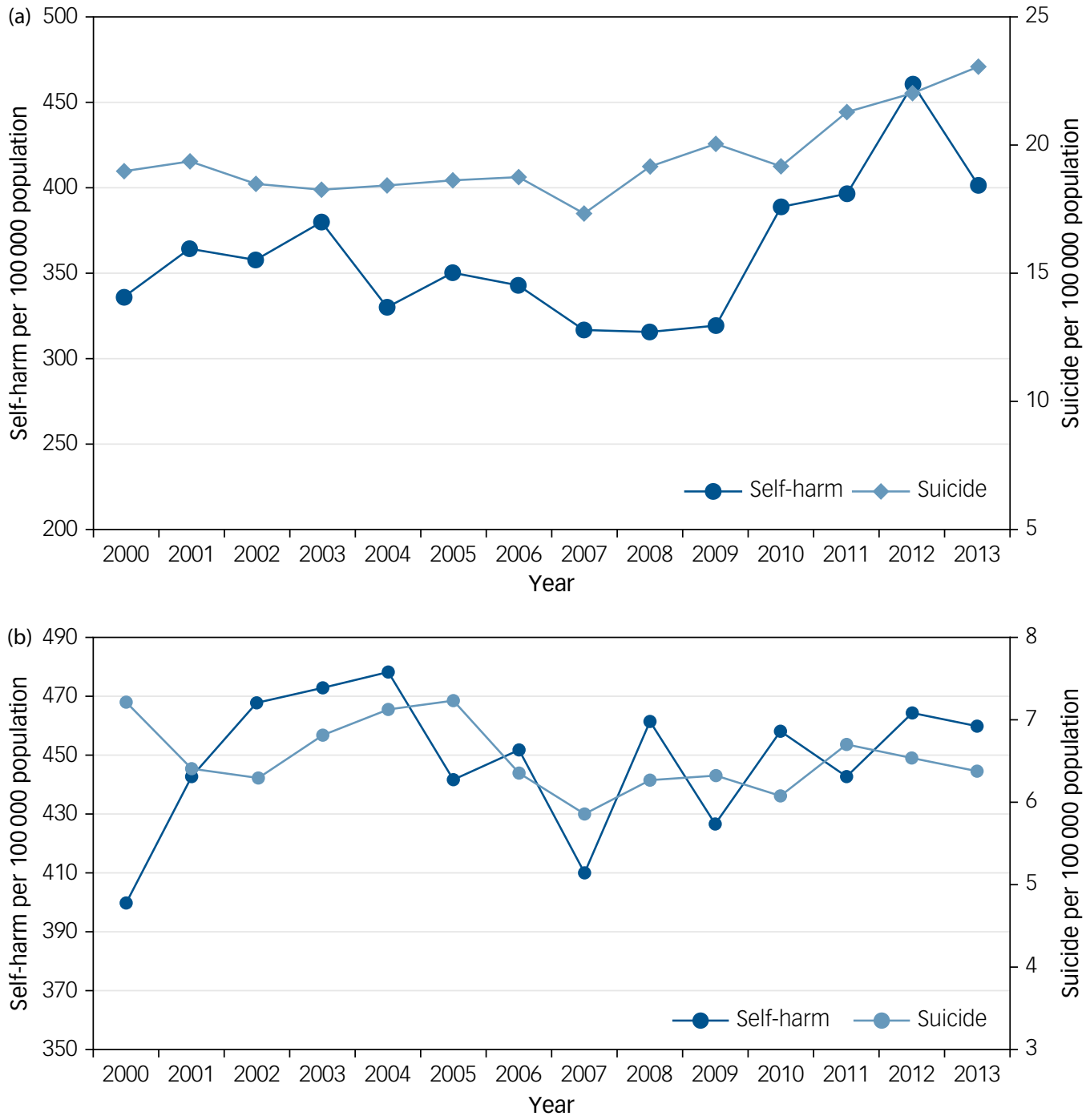

Fig. 2 (a) Rate of self-harm and national rate of suicide in men in midlife. (b) Rate of self-harm and rate of national suicide in women in midlife.

People in midlife with a lifetime first episode of self-harm were more likely to report problems around relationships and unemployment as precipitating self-harm. Those with a previous history of self-harm tended to report having more characteristics indicative of psychiatric and psychological morbidity as precipitating factors, such as alcohol problems (men odds ratio 1.42, 95\% CI 1.22-1.66, $P<0.05$; women odds ratio $1.45,95 \%$ CI $1.24-1.71$, $P<0.05$ ) and mental health problems (men odds ratio $1.51,95 \%$ CI $1.30-1.76, P<0.05$; women odds ratio $1.63,95 \%$ CI $1.42-1.87$, $P<0.05)$. High levels of previous psychiatric care were also associated with a previous history of self-harm in the midlife group (men odds ratio 5.05, 95\% CI 4.37-5.83, $P<0.01$; women odds ratio $5.03,95 \%$ CI $4.40-5.75, P<0.01$ ) (see Table $S 1$ ).

\section{Repetition of self-harm}

Between 2003 and 2012 there were 5943 men and 7229 women in midlife with an index presentation (first presentation in each calendar year) for self-harm. The 12-month repetition rate was $25 \%$ for both men (1503/5943) and women (1825/7229). Survival analysis showed that although men were less likely to repeat self-harm at any point during the study period after their first presentation (hazard ratio $0.92,95 \%$ CI $0.87-0.97, P=0.04$ ), they were more likely than women to repeat self-harm within 12 months (hazard ratio $1.12,95 \%$ CI $1.05-1.20, P<0.01$ ). However, when additional variables known to influence repetition of self-harm were entered into the model gender was no longer significant in terms of overall repetition (hazard ratio $0.94,95 \%$ CI $0.86-1.02, P=0.12$ ) or repetition within 12 months (hazard ratio 1.0 , 95\% CI 0.99 $1.22, P=0.06)$

\section{Mortality}

A total of 12534 individuals were followed up for mortality status. Of these, 1624 (13\%) had died by any cause (men $n=940$; women $n=684)$ and $10717(85 \%)$ were alive, with mortality status being unclear for a further 193 (2\%). Overall, 2.7\% of men (159/5856) and $1.2 \%$ of women in midlife died by suicide $(82 / 6678)$. Almost half of the suicides in men $(47 \%, n=75)$ and a third of those in women ( $34 \% ; n=28)$ occurred within the first 12 months following the index episode of self-harm. There was an increased risk of death overall in men compared with women (hazard ratio $1.69,95 \%$ CI $1.53-1.86, P<0.001$ ), but no gender difference in death by suicide (hazard ratio $1.23,95 \% \mathrm{CI} 0.94-1.62, P=0.13$ ). 
Table 2 Time-period comparisons of characteristics of men and women in midlife who attended hospital for self-harm, by year of first attendance

\begin{tabular}{|c|c|c|c|c|c|c|}
\hline Variable & $\begin{array}{c}\text { Men, } n(\%) \\
2002-2007 \\
(n=1752)\end{array}$ & $\begin{array}{l}\text { Men, } n(\%) \\
2008-2013 \\
(n=1760)\end{array}$ & $\begin{array}{l}\text { Odds ratio } \\
(95 \% \mathrm{Cl})\end{array}$ & $\begin{array}{l}\text { Women, } n(\%) \\
2002-2007 \\
(n=2058)\end{array}$ & $\begin{array}{l}\text { Women, } n(\%) \\
2008-2013 \\
(n=2005)\end{array}$ & $\begin{array}{l}\text { Odds ratio } \\
(95 \% \mathrm{Cl})\end{array}$ \\
\hline \multicolumn{7}{|l|}{ Method of self-harm ${ }^{a}$} \\
\hline Self-poisoning only & $1965(81.7)$ & 2025 (74.4) & $0.65(0.57-0.74)$ & $2496(88.5)$ & $2486(83.5)$ & $0.66(0.57-0.77)$ \\
\hline Self-injury only & 357 (14.9) & $600(22.0)$ & $1.62(1.40-1.87)$ & $266(9.4)$ & $426(14.3)$ & $1.60(1.36-1.89)$ \\
\hline Self-poisoning and self-injury & $82(3.4)$ & $98(3.6)$ & $1.06(0.78-1.43)$ & $60(2.1)$ & $65(2.2)$ & $1.03(0.72-1.47)$ \\
\hline Cutting or stabbing & $294(67.7)$ & $393(56.4)$ & $0.62(0.48-0.79)$ & $261(80.6)$ & $329(67.1)$ & $0.49(0.35-0.69)$ \\
\hline Jump from a height & $15(3.5)$ & $33(4.7)$ & $1.39(0.75-2.59)$ & $10(3.1)$ & $22(4.5)$ & $1.48(0.69-3.16)$ \\
\hline Hang/asphyxiation & $37(8.5)$ & $98(14.1)$ & $1.76(1.18-2.62)$ & $14(4.3)$ & $36(7.4)$ & $1.76(0.93-3.31)$ \\
\hline CO2 Gas & $29(6.7)$ & $36(5.2)$ & $0.76(0.46-1.26)$ & $4(1.2)$ & $5(1.0)$ & $0.82(0.22-3.09)$ \\
\hline $\begin{array}{l}\text { Alcohol consumed at time of self- } \\
\text { harm }\end{array}$ & $1081(65.2)$ & $1060(68.0)$ & $1.13(0.98-1.31)$ & $1188(61.5)$ & $1077(60.7)$ & $0.97(0.85-1.10)$ \\
\hline \multicolumn{7}{|l|}{ Employment } \\
\hline Employed & $657(40.8)$ & 630 (39.5) & $0.95(0.82-1.09)$ & $716(38.7)$ & $735(40.7)$ & $1.08(0.95-1.24)$ \\
\hline Unemployed & $541(33.6)$ & $730(45.8)$ & $1.67(1.45-1.92)$ & $494(26.7)$ & $661(36.6)$ & $1.58(1.37-1.82)$ \\
\hline Registered sick/disability & 344 (21.4) & $168(10.5)$ & $0.43(0.35-0.53)$ & 358 (19.4) & 203 (11.2) & $0.53(0.44-0.63)$ \\
\hline Household duties & $7(0.4)$ & $4(0.3)$ & $0.58(0.17-1.97)$ & $215(11.6)$ & $157(8.7)$ & $0.72(0.58-0.90)$ \\
\hline Other employment & $24(1.5)$ & $33(2.1)$ & $1.39(0.82-2.37)$ & $22(1.2)$ & $27(1.5)$ & $1.26(0.71-2.22)$ \\
\hline White & $1512(95.6)$ & $1550(93.8)$ & $0.69(0.51-0.95)$ & $1777(94.5)$ & $1753(93.4)$ & $0.83(0.63-1.08)$ \\
\hline Black & $22(1.4)$ & $25(1.5)$ & $1.09(0.61-1.94)$ & $33(1.8)$ & $36(1.9)$ & $1.10(0.68-1.76)$ \\
\hline South Asian & $26(1.6)$ & $38(2.3)$ & $1.41(0.85-2.33)$ & $48(2.6)$ & $42(2.2)$ & $0.87(0.57-1.33)$ \\
\hline Other ethnicity & $21(1.3)$ & $39(2.4)$ & $1.80(1.05-3.07)$ & $23(1.2)$ & $46(2.5)$ & $2.03(1.23-3.36)$ \\
\hline $\begin{array}{l}\text { Any previous self-harm } \\
\text { (self-reported) }\end{array}$ & $774(50.5)$ & $873(54.0)$ & $1.15(1.00-1.32)$ & 1015 (55.9) & $1053(57.2)$ & $1.05(0.92-1.20)$ \\
\hline Self-harm $<12$ months & $310(20.2)$ & $369(22.8)$ & $1.17(0.98-1.38)$ & $339(18.7)$ & $389(21.1)$ & $1.17(0.99-1.37)$ \\
\hline Self-harm >12 months & $423(27.6)$ & 496 (30.7) & $1.16(0.99-1.35)$ & $627(34.6)$ & $662(35.9)$ & $1.06(0.93-1.22)$ \\
\hline Current psychiatric treatment & $650(40.7)$ & $863(51.8)$ & $1.57(1.37-1.80)$ & $942(49.1)$ & $1090(57.5)$ & $1.40(1.23-1.59)$ \\
\hline $\begin{array}{l}\text { Previous psychiatric treatment } \\
\text { (under secondary mental health } \\
\text { services) }\end{array}$ & $877(55.9)$ & $968(59.8)$ & $1.18(1.02-1.35)$ & $1139(60.8)$ & 1125 (60.5) & $0.99(0.87-1.13)$ \\
\hline \multicolumn{7}{|l|}{$\begin{array}{l}\text { Referral from the emergency } \\
\text { department }{ }^{\mathrm{b}}\end{array}$} \\
\hline Admitted to medical bed & $889(70.8)$ & $1119(70.3)$ & $0.98(0.83-1.15)$ & $1115(73.6)$ & $1330(72.0)$ & $0.92(0.79-1.08)$ \\
\hline Psychiatric outpatient care & $555(31.6)$ & $701(39.9)$ & $1.43(1.25-1.65)$ & $676(32.8)$ & $794(39.7)$ & $1.35(1.19-1.53)$ \\
\hline Psychiatric inpatient care & $144(8.2)$ & $170(9.7)$ & $1.20(0.95-1.51)$ & $117(5.7)$ & $115(5.7)$ & $1.00(0.77-1.31)$ \\
\hline Self-discharged & $35(2.0)$ & $38(2.2)$ & $1.09(0.68-1.73)$ & $26(1.3)$ & $48(2.4)$ & $1.92(1.18-3.10)$ \\
\hline GP care ${ }^{\mathrm{c}}$ & $962(56.4)$ & $612(37.8)$ & $0.47(0.41-0.54)$ & $1210(61.1)$ & $780(42.6)$ & $0.47(0.41-0.54)$ \\
\hline Drug and alcohol services & $118(7.1)$ & $219(12.8)$ & $1.93(1.52-2.44)$ & $98(4.9)$ & $154(7.9)$ & $1.66(1.28-2.15)$ \\
\hline \multicolumn{7}{|l|}{ Precipitants of self-harm } \\
\hline $\begin{array}{l}\text { Relationship problems - partner/ } \\
\text { family/friends/others }\end{array}$ & $912(51.9)$ & $942(53.5)$ & $1.07(0.93-1.22)$ & $1275(61.8)$ & $1180(58.7)$ & $0.88(0.77-0.99)$ \\
\hline Employment or study problems & $280(16.8)$ & 485 (28.4) & $1.97(1.67-2.33)$ & $202(10.3)$ & $362(18.6)$ & $1.99(1.66-2.40)$ \\
\hline Financial problems & $295(17.7)$ & 434 (25.5) & $1.59(1.35-1.88)$ & $293(14.9)$ & $417(21.4)$ & $1.56(1.32-1.84)$ \\
\hline Housing problems & $262(15.7)$ & $342(20.1)$ & $1.35(1.13-1.61)$ & $190(9.7)$ & $307(15.8)$ & $1.75(1.44-2.12)$ \\
\hline Alcohol problems $^{\mathrm{d}}$ & 366 (31.3) & $614(36.0)$ & $1.23(1.05-1.44)$ & 317 (23.0) & $524(26.9)$ & $1.24(1.05-1.45)$ \\
\hline Drug problems ${ }^{\mathrm{d}}$ & $54(4.6)$ & $137(8.0)$ & $1.80(1.30-2.49)$ & $28(2.0)$ & $74(3.8)$ & $1.91(1.23-2.97)$ \\
\hline Legal problems & $111(6.6)$ & $139(8.2)$ & $1.25(0.96-1.61)$ & $55(2.8)$ & $92(4.7)$ & $1.72(1.23-2.42)$ \\
\hline Physical health problems & $277(16.6)$ & $263(15.4)$ & $0.92(0.76-1.10)$ & $296(15.1)$ & $296(15.2)$ & $1.01(0.85-1.20)$ \\
\hline Mental health problems & $362(21.7)$ & 516 (30.3) & $1.57(1.34-1.83)$ & $468(23.8)$ & $662(34.0)$ & $1.65(1.43-1.89)$ \\
\hline
\end{tabular}

\section{Discussion}

A quarter of all self-harm presentations from 2000 to 2013 (inclusive) in the Multicentre Study of Self-harm in England were by men and women in midlife. Rates of self-harm were higher in women than in men (449 and 363 per 100 000), but rates in men increased over time, especially after 2008 , whereas they remained stable over time in women. A quarter of both men and women repeated self-harm within 12 months of an episode, exceeding the 16\% 12-month repetition rate found in all-age samples. ${ }^{7}$ Suicide mortality was $2.7 \%$ in men and $1.2 \%$ in women during the follow-up period, consistent with the results of meta-analytic work on overall fatal repetition across all ages. ${ }^{7}$ Risk of suicide was particularly high within 12 months of an episode of self-harm, especially in men.
Although there were statistically significant differences in characteristics between men and women, these differences were mainly small, and men and women were broadly similar overall. However, there may be a gender-based difference in the importance of socioeconomic factors and alcohol use as well as mental ill health in relation to self-harm. In men, self-harm was more often characterised by alcohol use within $6 \mathrm{~h}$ before self-harm, unemployment and precipitating problems relating to finances and housing. Self-harm in women was more often associated with indicators of mental ill health, such as previous self-harm, and current and/or previous psychiatric care. These results are in line with previous work that identified women as reporting more mental healthrelated problems as key precipitants to self-harm. ${ }^{14}$

The cohort comparison showed that socioeconomic and mental health-related factors have become more common antecedents of 
self-harm over time. Self-harm in the more recent cohort was more often associated with characteristics related to economic distress including high unemployment, problems with finances, and difficulties with housing. These factors are known to be related to increases in suicidal behaviour and may have driven a rise in selfharm in middle-aged men., ${ }^{9,2,24}$ There is evidence that the economic recession of 2008 prompted increases in self-harm in England and overseas, ${ }^{12,25,26}$ which is of concern given the positive correlation between rates of self-harm and suicide. ${ }^{8,15}$ Not only do the results of the cohort comparison support this idea but it may be that the recession-related rise in self-harm in men in midlife might be greater than the rise in suicide (see Fig. 2a).

An increase over time in people under current psychiatric care and reporting mental health problems as precipitants of self-harm may indicate more awareness of mental health issues as well as improved access to services, in line with recommendations. ${ }^{1}$ Alternatively it may reflect a broader increase in mental ill health within the midlife age group. ${ }^{27}$

Referrals to drug and alcohol services increased over time across genders. However, total numbers remained small (men 378, 9\%; women 275, 6\%). Given that alcohol ingestion associated with self-harm was common at $66 \%$ in men and $62 \%$ in women - and higher than found in broader self-harm samples ${ }^{13,28,29}$ - and the frequency with which alcohol problems are cited as a precipitating factor, improved access to drug, alcohol and dual diagnosis services may be an important area for reducing self-harm in midlife and should be considered when creating care pathways.

People who self-harm for the first time in midlife seemed to be influenced by more transitory and situational factors, such as socioeconomic factors and problems in relationships, compared with the more long-term indicators of poor mental health and psychiatric illness associated with people in midlife with a history of self-harm. It could be that a sudden major stressor such as job loss or family breakdown is more likely to precipitate a first episode of self-harm in this age group. The potential transition from situational-related first episodes to repeat episodes with increasing indicators of poor mental health emphasises the importance of providing effective early support and intervention. Repetition of self-harm in midlife was associated with more psychiatric factors and some authors have speculated that this may reflect a broader increase in mental ill health in the midlife age group. ${ }^{27}$

\section{Limitations}

This study only included self-harm by people who presented to hospital and therefore the results may not be generalisable to people in midlife who self-harm in community settings. However, those who do present to hospital are an important group, well positioned to take advantage of intervention and prevention strategies.

We used data from three predominantly urban areas in England which may not reflect self-harm in other locations or more rural areas. However, predominantly urban populations are known to have higher rates of self-harm and a strength of the Multicentre Study is the combination of data from areas with very different demographic and economic profiles which, together, provide a more representative picture of self-harm across England. ${ }^{30}$

In the comparative analyses only cases that received a specialist assessment, and/or an assessment by emergency department staff in Manchester, were included (apart from methods of harm variables where all available data were included). There is evidence of systematic differences between people who do and do not receive a psychiatric assessment following self-harm due to administrative and clinical reasons (e.g. refusing an assessment, self-discharge from the emergency department before being seen, no referral to psychiatric liaison made by emergency department staff) and this may be a source of bias within the data. ${ }^{31}$ In addition, where all data were included (method of harm variables), information on non-assessed cases was only available in Manchester from 2003 onwards.

\section{Implications}

Given the strong link with suicide, hospital presentations for selfharm may be a key point for suicide prevention in this midlife age group. Perhaps especially in men, who are seen as hard to reach and known to be less likely to seek traditionally recognised help for mental health problems. ${ }^{32}$ Over a third of people in midlife who attended hospital following self-harm were not given a specialist psychiatric assessment and therefore opportunities to tackle issues around alcohol use, economic factors and underlying mental illness may be missed. Access to a full psychosocial assessment might be especially important for men in midlife who tended to have lower rates of contact with mental health services overall.

Alcohol use was common but referrals to drug and alcohol services remained low, indicating a continuing need for increased access to alcohol services. Economic factors had a clear link with self-harm in midlife and tackling these issues may require health and mental health services to work with organisations offering advice on employment, housing and debt. Signposting to social/ employment support services may be bolstered by providing more detailed information or arranging contacts to encourage engagement.

Middle-aged men are a priority group for suicide prevention, as set out in the third update of the Suicide Prevention Strategy for England. ${ }^{1}$ Campaigns to raise awareness, reduce stigma and encourage help seeking for suicide and other mental health issues often target traditionally male spaces, such as sporting communities, and similar strategies could be used to raise awareness of selfharm. Men in midlife were less likely than women to have previously accessed psychiatric services and therefore targeting barriers that prevent men in this age group from seeking help for mental health problems should be prioritised, along with consideration of what interventions and services would best meet their needs.

Caroline Clements (D., PhD, Research Associate, Centre for Mental Health and Safety, Manchester Academic Health Sciences Centre, The University of Manchester, UK; Keith Hawton, DSC, FRCPsych, Professor of Psychiatry, Centre for Suicide Research, Department of Psychiatry, University of Oxford, UK; Galit Geulayov, PhD, Study Coordinator, Centre for Suicide Research, Department of Psychiatry, University of Oxford, UK: Keith Waters, Director, Centre for Self-harm and Suicide Prevention Research, Derbyshire Healthcare National Health Service Foundation Trust, UK; Jennifer Ness, MSc, Lead Health Services Researcher, Centre for Self-harm and Suicide Prevention Research, Derbyshire Healthcare National Health Service Foundation Trust, UK; Muzamal Rehman, MSc, Research Assistant, Centre for Self-harm and Suicide Prevention Research, Derbyshire Healthcare National Health Service Foundation Trust, UK; Ellen Townsend, PhD, Professor of Psychology, Self-Harm Research Group, School of Psychology, University of Nottingham, UK; Louis Appleby, MD, FRCPsych, Professor of Psychiatry, Centre for Mental Health and Safety, Manchester Academic Health sciences Centre, The University of Manchester, UK; Nav Kapur, MD, FRCPSych, Sciences Centre, The University of Manchester, UK; Nav Kapur, MD, FRCPSych,
Professor of Psychiatry and Population Health, Centre for Mental Health and Safety, Manchester Academic Health Sciences Centre, The University of Manchester; and Honorary Consultant in Psychiatry, Greater Manchester Mental Health National Health Service Foundation Trust, UK

Correspondence: Caroline Clements, Centre for Mental Health and Safety, Division of Psychology and Mental Health, The University of Manchester, Room 2.308, Jean

McFarlane Building, Oxford Road, Manchester M13 9PL, UK. Email: caroline.v.clements@ manchester.ac.uk

First received 19 Aug 2018, final revision 27 Jan 2019, accepted 12 Mar 2019

\section{Supplementary material}

Supplementary material is available online at https://doi.org/10.1192/bjp.2019.90. 


\section{References}

1 Department of Health. Preventing Suicide in England: Third Progress Report of the Cross-Governmental Outcomes Strategy to Save Lives. Department of Health, 2017 (https://www.gov.uk/government/uploads/system/uploads/ attachment_data/file/582117/Suicide_report_2016_A.pdf).

2 World Health Organization. Preventing Suicide: A Global Imperative. World Health Organization, 2014

3 Hawton K, Zahl D, Weatherall R. Suicide following deliberate self-harm: longterm follow-up of patients who presented to a general hospital. Br J Psychiatry 2003: 182: 537-42.

4 Centers for Disease Control and Prevention. Fatal Injury Reports 2015. Centres for Disease Control and Prevention, 2015 (https://www.cdc.gov/injury/ wisqars/fatal.html)

5 Australian Bureau of Statistics. Catalogue 3303.0 Causes of Death Australia. Australian Bureau of Statistics, 2016.

6 Hawton K, Zahl D, Weatherall R. Suicide following deliberate self-harm: long-term follow-up of patients who presented to a general hospital Suicide following deliberate self-harm : long-term follow-up of patients who presented to a general hospital. Br J Psychiatry 2003; 182: 537-42.

7 Carroll R, Metcalfe C, Gunnell D. Hospital presenting self-harm and risk of fata and non- fatal repetition: Systematic review and meta-analysis. PLOS ONE 2014; 9: e89944.

8 Geulayov G, Kapur N, Turnbull P, Clements C, Waters K, Ness J, et al. Epidemiology and trends in non-fatal self-harm in three centres in England, 2000-2012: findings from the Multicentre Study of Self-harm in England. BMJ Open 2016; 6: e010538.

9 Haw C, Hawton K, Gunnell D, Platt S. Economic recession and suicidal behaviour: possible mechanisms and ameliorating factors. Int J Soc Psychiatry 2015; 61: 73-81.

10 Hempstead KA, Phillips JA. Rising suicide among adults aged 40-64 years: the role of job and financial circumstances. Am J Prev Med 2015; 48: 491-500.

11 Coope C, Donovan J, Wilson C, Barnes M, Metcalfe C, Hollingworth W, et al. Characteristics of people dying by suicide after job loss, financial difficulties and other economic stressors during a period of recession (2010-2011): a review of coroners' records. J Affect Disord 2015; 183: 98-105.

12 Hawton K, Bergen H, Geulayov G, Waters K, Ness J, Cooper J, et al. Impact of the recent recession on self-harm: Iongitudinal ecological and patient-level investigation from the Multicentre Study of Self-harm in England. $J$ Affect Disord 2016; 191: 132-8.

13 Ness J, Hawton K, Bergen H, Cooper J, Steeg S, Kapur N, et al. Alcohol use and misuse, self-harm and subsequent mortality: an epidemiological and longitudinal study from the multicentre study of self-harm in England. Emerg Med $\mathrm{J}$ 2015; 32: 793-9.

14 Townsend E, Ness J, Waters K, Kapur N, Turnbull P, Cooper J, et al. Self-harm and life problems: findings from the Multicentre Study of Self-harm in England. Soc Psychiatry Psychiatr Epidemiol 2016; 51: 183-92.

15 Hawton K, Bergen H, Casey D, Simkin S, Palmer B, Cooper J, et al. Self-harm in England: a tale of three cities. Multicentre study of self-harm. Soc Psychiatry Psychiatr Epidemiol 2007; 42: 513-21.
16 Office for National Statistics. Suicides in the UK: 2016 Registrations. Office for National Statistics, 2017 (https://www.ons.gov.uk/peoplepopulationandcommunity/birthsdeathsandmarriages/deaths/bulletins/suicidesintheunitedkingdom/2016registrations).

17 Lassus LAP, Lopez S, Roscigno VJ. Aging workers and the experience of job loss. Res Soc Stratif Mobil 2015; 41: 81-91.

18 Kelley CP, Soboroff SD, Lovaglia MJ. The status value of age. Soc Sci Res 2016; 66: 22-31

19 Liebler CA, Sandefur GD. Gender differences in the exchange of social support with friends, neighbors, and co-workers at midlife. Soc Sci Res 2002; 31: 364-91.

20 Lee $D$, Jackson $M$. The relationship between lifetime health trajectories and socioeconomic attainment in middle age. Soc Sci Res 2015; 54: 96-112.

21 Gunnell D, Bennewith O, Simkin S, Cooper J, Klineberg E, Rodway C, et al. Time trends in coroners' use of different verdicts for possible suicides and their impact on officially reported incidence of suicide in England: 1990-2005. Psychol Med 2013; 43: 1415-22.

22 Gosney H, Hawton K. Inquest verdicts: youth suicides lost. Psychiatr Bull 2007; 31: 203-5.

23 Palmer BS, Bennewith O, Simkin S, Cooper J, Hawton K, Kapur N, et al. Factors influencing coroners' verdicts: an analysis of verdicts given in 12 coroners' districts to researcher-defined suicides in England in 2005. J Public Health (Oxf) 2015; 37: 157-65.

24 Coope C, Gunnell D, Hollingworth W, Hawton K, Kapur N, Fearn V, et al. Suicide and the 2008 economic recession: who is most at risk? Trends in suicide rates in England and Wales 2001-2011. Soc Sci Med 2014; 117: 76-85.

25 Economou M, Madianos M, Peppou LE, Theleritis C, Patelakis A, Stefanis C. Suicidal ideation and reported suicide attempts in Greece during the economic crisis. World Psychiatry 2013; 12: 53-9.

26 Córdoba-Doña JA, San Sebastián M, Escolar-Pujolar A, Martínez-Faure JE, Gustafsson PE. Economic crisis and suicidal behaviour: the role of unemployment, sex and age in Andalusia, Southern Spain. Int J Equity Health 2014; 13: 1-10.

27 Olfson M, Wang S, Blanco C. National trends in hospital-treated self-harm events among middle-aged adults. Gen Hosp Psychiatry 2015; 37: 613-9.

28 Haw C, Hawton K, Casey D, Bale E, Shepherd A. Alcohol dependence, excessive drinking and deliberate self-harm. Soc Psychiatry Psychiatr Epidemiol 2005; 40: 964-71.

29 Griffin E, Arensman E, Perry IJ, Bonner B, O'Hagan D, Daly C, et al. The involvement of alcohol in hospital-treated self-harm and associated factors: findings from two national registries. J Public Health (Bangkok) 2017: 1-7.

30 Harriss $L$, Hawton $K$. Deliberate self-harm in rural and urban regions: a comparative study of prevalence and patient characteristics. Soc Sci Med 2011; 73: 274-81

31 Kapur N, Murphy E, Cooper J, Bergen H, Hawton K, Simkin S, et al. Psychosocial assessment following self-harm: results from the Multi-Centre Monitoring of Self-Harm Project. J Affect Disord 2008; 106: 285-93.

32 Yousaf $O$, Grunfeld EA, Hunter MS. A systematic review of the factors associated with delays in medical and psychological help-seeking among men. Health Psychol Rev 2015: 9: 264-76. 